\title{
Development and Validation of an HPLC-UV Method for Quantitation of Linezolid: Application to Resistance Study Using in vitro PK/PD Model
}

\author{
Guang Yang $\mathbb{D}^{1,2}$ \\ Yisong Yan ${ }^{1,3}$ \\ Jun Mao' \\ Huiping Liu' \\ Mingtao Chen' \\ Na Zhang' \\ Yaowen $\mathrm{Li}^{1}$ \\ Jiangjun $\mathrm{Gu}^{2}$ \\ Xiaohui Huang' \\ 'Department of Basic and Clinical \\ Pharmacology, School of Pharmacy, Anhui \\ Medical University, Hefei, Anhui, People's \\ Republic of China; ${ }^{2}$ Department of \\ Pharmacy, The Third People's Hospital of \\ Tongling, Tongling, Anhui, People's \\ Republic of China; ${ }^{3}$ Department of \\ Pharmacy, Anhui College of Traditional \\ Chinese Medicine, Wuhu, Anhui, People's \\ Republic of China
}

Correspondence: Xiaohui Huang Department of Basic and Clinical Pharmacology, School of Pharmacy, Anhui Medical University, Meishan Road 8I\#, Hefei, Anhui, 230032, People's Republic of China

Tel +8613855183138

Email math2088@I63.com
Background: Linezolid (LNZ), an oxazolidinone antibiotic, has 100\% oral bioavailability and favorable activities against gram-positive pathogens. The in vitro PK/PD model was developed based on concentrations obtained with routine doses in humans can be used to guide dose optimization in the clinic.

Methods: In this study, we employed an in vitro PK/PD model to simulate the changes in the plasma concentration of linezolid in the human body against a clinical isolate of MRSA in vitro. A high-performance liquid chromatography (HPLC)-UV method was applied to measure the concentration of linezolid. Bacterial samples were collected at different times from the central compartment for count.

Results: The chromatographic separation was carried out with an AichromBond-AQC18 column $(250 \mathrm{~mm} \times 4.6 \mathrm{~mm}, 5 \mu \mathrm{m})$, using a mobile phase of water with $0.1 \%$ formic acid:acetonitrile $70: 30$ $(\mathrm{v} / \mathrm{v})$, followed by detection at $254 \mathrm{~nm}$, and a single detection run was completed within $10 \mathrm{~min}$. The method was validated by estimating the precision and accuracy for the inter- and intra-day analyses in the concentration range of $0.25-32 \mathrm{mg} / \mathrm{L}$. The method was linear over the investigated range of $0.125-32 \mathrm{mg} / \mathrm{L}$, with all correlation coefficients $\mathrm{R}^{2}=0.9999$. The intra-day and inter-day precisions were within $7.598 \%$, and the method recovery ranged from $90.912 \%$ to $106.459 \%$. In vitro PK/PD model, both the absorption and elimination of linezolid being simulated can be precisely controlled by computer. In the control group, the bacterial reached $7.9 \mathrm{Log} 10 \mathrm{CFU} / \mathrm{mL}$ in the first $48 \mathrm{~h}$ and maintained until the end, indicating that the colonies grew well in vitro PK/PD model. In the linezolid $600 \mathrm{mg}$ q12h administration group, the colony decreased to 2.39 $\log 10 \mathrm{CFU} / \mathrm{mL}$ at $24 \mathrm{~h}$, showing a good bactericidal effect; however, the colonies resumed growth to the initial level in $48 \mathrm{~h}$, indicating an emergence of resistance.

Conclusion: We successfully established an in vitro infection PK/PD model and developed an HPLC-UV method to determine linezolid concentration for resistance investigation. The results suggest that the $600 \mathrm{mg} \mathrm{q1} \mathrm{h}$ dosing regimen may no longer be applicable and requires optimization.

Keywords: linezolid, HPLC-UV, PK/PD model, resistance

\section{Introduction}

There is globally a critical need for new and effective antibiotics. Linezolid (LNZ) can be the treatment of choice for a variety of gram-positive bacteria including penicillin-resistant Streptococcus pneumoniae, Methicillin-resistant Staphylococcus aureus (MRSA), glycopeptide intermediate Staphylococcus aureus, vancomycinresistant enterococci (VRE), and so on. ${ }^{1}$ However, clinical isolates resistant to linezolid have been reported including MRSA and VRE. ${ }^{2}$ 
With the emergence of resistant bacteria, the usual administration regimen of LNZ may not be efficacious. There is an urgency for dose optimization in clinical settings. Compared with the traditional in vitro static timekill experiments and animal infection models, PK/PD simulations carried out with in vitro models provide important $\mathrm{PK} / \mathrm{PD}$ information for dose optimization. ${ }^{3-5}$ We employed an in vitro PK/PD model and simulated an intermittent intravenous dose of $600 \mathrm{mg} \mathrm{q} 12 \mathrm{~h}$ against a clinical isolate for 3 days treatment with linezolid. ${ }^{6}$

A rapid and reliable analytical method to quantify the concentration is required. High-performance liquid chromatography (HPLC) methods involving different sample handling methods such as deproteinization ${ }^{7,8}$ and solidphase extraction ${ }^{9,10}$ have been proposed for LNZ determination in plasma, serum, urine, and microdialysis samples, and an on-line extraction technique has also been applied to Mueller-Hinton Broth (MHB) samples. ${ }^{11}$ HPLC can be considered an adequate technique for determining LNZ in MHB. The sensitivity and precision of HPLC and its applicability to a wide variety of compounds have resulted in its use in clinical laboratories for monitoring a variety of therapeutic agents in hospital settings, as well as pharmacokinetic and metabolism studies. Most of the methods reported measure the concentration of LNZ in plasma that may not suit for applying in broth. Therefore, we need to establish new methods to detect it. In addition, the established methods need to be rapidly and accurately applied to determine a large number of samples in vitro PK/PD mode.

To effectively monitor the drug concentration under bacterial infection, we developed and validated a deproteinization method for LNZ determination in MHB, using a simple and accurate HPLC-UV method that enabled the quantification of LNZ in vitro and provided a basis for its further application in vitro drug resistance study. The application of fully automatic injection technology allows us to determine large numbers of samples accurately and quickly.

\section{Materials and Methods}

\section{Chemicals and Isolates}

LNZ was commercially obtained from Pfizer and the National Institute for Food and Drug Control of China (Beijing China). HPLC-grade acetonitrile and formic acid were provided by Macklin (Shanghai, China). HPLCgrade water was produced using a Milli-Q system.
Mueller-Hinton Broth (MHB) and Mueller-Hinton Agar (MHA) were purchased from Oxoid (England), MRSA clinical isolate and ATCC 29213 were acquired from The First Affiliated Hospital of AHMU. MRSA sample was isolated from the sputum of a patient admitted to the first affiliated hospital of Anhui Medical University as part of routine care. In addition, the clinical strain was not specifically isolated for this research, but they were part of the routine hospital microbiology laboratory procedure. This study was approved by the First Affiliated Hospital of Anhui Medical University institutional review board. ATCC 29213 was used as quality control in susceptibility testing.

\section{Determination of MIC}

According to CLSI, ${ }^{12}$ the MIC of linezolid was performed using the broth microdilution method in 96-well plates by adding a series of twofold dilutions of the antimicrobial drug followed by a 150 -fold dilution of the logarithmic growth phase bacterial solution (approximately $1.5 \times 10^{8}$ $\mathrm{CFU} / \mathrm{mL}$ ) to the small wells. The plates were incubated at $37^{\circ} \mathrm{C}$ for $24 \mathrm{~h}$ and the results were observed at the lowest drug concentration without visible bacterial growth as MIC. ATCC29213 was used as a quality control strain and the experiment was replicated three times.

\section{Preparation of Stock Solutions, Calibration Standards, and Quality Control Samples}

The stock solution was prepared by mixing standard LNZ (Beijing China) in water reached $1000 \mathrm{mg} / \mathrm{L}$ and preserved in the absence of light, working solutions of LNZ were prepared by mixing an accurately weighed volume of the stock solution with water to yield final concentrations of $320,160,80,40,20,10,5,2.5$ and $1.25 \mathrm{mg} / \mathrm{L}$. Calibration standards were prepared by diluting working solutions of LNZ in broth to yield LNZ concentrations of 32, 16, 8, 4, $2,1,0.5,0.25$ and $0.125 \mathrm{mg} / \mathrm{L}$. Quality control (QC) samples were obtained by diluted the working solutions of LNZ in broth at high, medium and low concentrations of 32,16 and $0.25 \mathrm{mg} / \mathrm{L}$.

\section{Sample Preparation}

Protein precipitation was performed using in MHB samples from an in vitro PK/PD model. Briefly, $1 \mathrm{~mL}$ of broth sample was taken from the in vitro PK/PD model stored at $-20{ }^{\circ} \mathrm{C}$ until analysis. Before analysis, the preserved 
samples were thawed and centrifuged at 12,000 rpm for 10 min. The supernatants were filtered through a $0.22-\mu \mathrm{m}$ membrane and $100 \mu \mathrm{L}$ of the supernatants were added to $200 \mu \mathrm{L}$ of acetonitrile and vortexed for $1 \mathrm{~min}$. The samples were re-centrifuged at $12,000 \mathrm{rpm}$ for $10 \mathrm{~min}$ and $20 \mu \mathrm{L}$ of the supernatant was injected into the HPLC-UV equipment, the calibration standards and quality control samples in broth were processed in the same manner.

\section{HPLC-UV Instruments and Analytical Conditions}

The HPLC system used was Shimadzu LC-20AD highperformance liquid chromatograph, SIL-20A autosampler, SPD-20A UV detector, CTO-20A column temperature chamber, CBM-20A system controller (Kyoto, Japan). A $250 \mathrm{~mm} \times 4.6$ AichromBond-AQ C18 chromatographic column with $5 \mu \mathrm{m}$ particles was used. The mobile phase was water with $0.1 \%$ formic acid: acetonitrile 70:30 (v/v). The flow rate was $1 \mathrm{~mL} / \mathrm{min}$, and the injection volume was $20 \mu \mathrm{L}$. The column temperature was maintained at $35^{\circ} \mathrm{C}$ and detection was monitored at a wavelength of $254 \mathrm{~nm}$.

\section{In vitro PK/PD Model}

The in vitro PK/PD model utilized MRSA clinical isolate. The isolates stored at $-20^{\circ} \mathrm{C}$ were inoculated on an agar plate for $24 \mathrm{~h}$ at $37^{\circ} \mathrm{C}$. A single fresh colony was taken from the agar plate, suspended in fresh broth and cultured overnight at $37{ }^{\circ} \mathrm{C}$ and $200 \mathrm{rpm}$ to reach the logarithmic growth phase; an appropriate amount of bacteria was added into the broth and vortexed to reach 0.5 McFarland. Then, $2 \mathrm{~mL}$ of the prepared bacterial suspension was added to the central compartment yield $10^{5}-10^{6} \mathrm{CFU} / \mathrm{mL}$. The bacteria were exposed to LNZ with multiple doses of $600 \mathrm{mg} \mathrm{q} 12 \mathrm{~h}$ with a 0.5 $\mathrm{h}$ continuous infusion for 3 days. ${ }^{13,14}$ The simulated concentration of LNZ in vitro PK/PD model was achieved by controlling the flow rate of the peristaltic pump using a computer. Bacterial and drug samples were collected at different times from the central compartment for analysis.

\section{Method Validation Linearity}

Calibration curves were prepared by assaying standard broth samples at 9 different concentrations. The linearity of each calibration curve was determined by plotting the peak area versus the nominal concentration of analytes with weighted $\left(1 / \mathrm{x}^{2}\right)$ least-square linear regression.

\section{Accuracy and Precision}

Five QC samples of MHB with three concentrations of LNZ $(0.25,16$, and $32 \mathrm{mg} / \mathrm{L})$ were prepared. Inter-day accuracy and precision were assessed by analyzing QC samples in three replicates at three concentration levels on three different days. Intra-day accuracy and precision were assessed by analyzing QC samples in three replicates at three concentration levels on the same day using the same calibration curve. The accuracy for each QC concentration level was expressed as recovery by calculating the percentage bias from the nominal concentration of the quality-control samples. The precision for each QC concentration was expressed as $\mathrm{CV}$ (Coefficient of Variation) by calculating the standard deviation as a percentage of the mean calculated concentration.

\section{Stability Study}

Studies were conducted to evaluate the stability of the analytes under different storage conditions: at $4{ }^{\circ} \mathrm{C}$ (up to $24 \mathrm{~h}$ ), freeze-thaw at $-20{ }^{\circ} \mathrm{C}$ (three cycles) and at room temperature (up to $24 \mathrm{~h}$ ). Experiments were performed at the lower quality control (LQC), middle quality control (MQC) and higher quality control (HQC) concentrations for LNZ. The measured concentrations were compared to nominal values. The samples were stable if the deviation was $\pm 15 \%$ of the nominal values.

\section{Software}

Certara Phoenix WinNonlin 8.3 was used for pharmacokinetic simulation (Princeton, NJ, USA). IBM SPSS statistics 25 (New York, NY USA) was used for one-way analysis of variance (ANOVA). $\mathrm{P}<0.05$ indicated a statistically significant difference. Plotting was performed using origin 9.0 (MA, USA).

\section{Results \\ MIC}

The broth microdilution linezolid MIC for this isolate was $2 \mathrm{mg} / \mathrm{L}$.

\section{HPLC-UV Chromatograms}

Under the above analytical conditions, the chromatographic peak shape of LNZ was good, no apparent interference from endogenous substances was detected. The retention time of LNZ was $7.4 \mathrm{~min}$. Figure 1 shows the chromatograms of blank broth, broth containing LNZ and the chromatogram of LNZ in the pure water sample. 

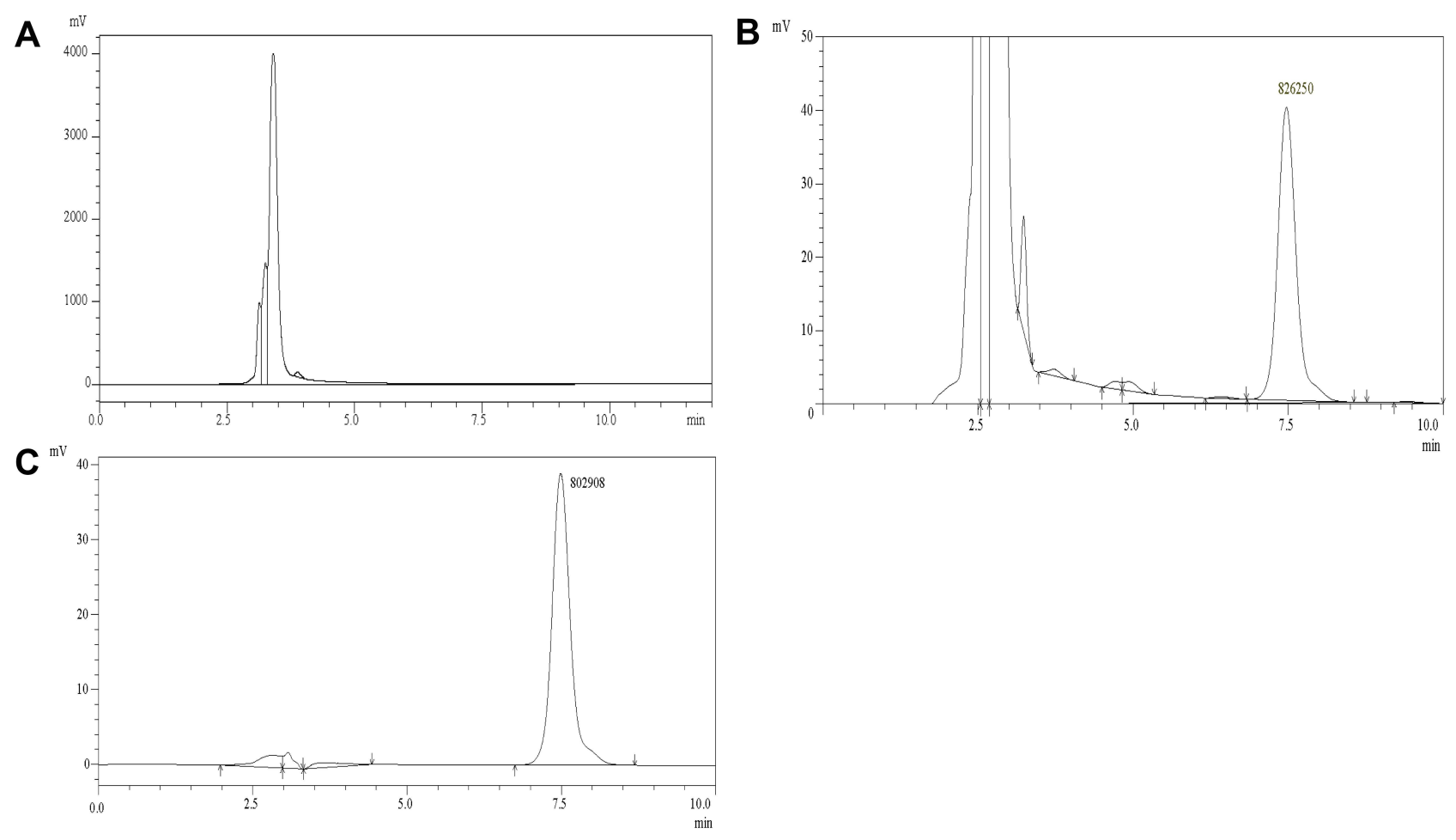

Figure I Chromatograms: (A) blank broth, (B) broth sample spiked with LNZ, (C) water sample spiked with LNZ.

\section{Linearity}

The linearity of the method was evaluated at nine nonzero concentrations ranging from 0.125 to $32 \mathrm{mg} /$
L. A regression equation was employed to establish the best fit for the concentration-peak area response relationship (Figure 2). The correlation coefficient of

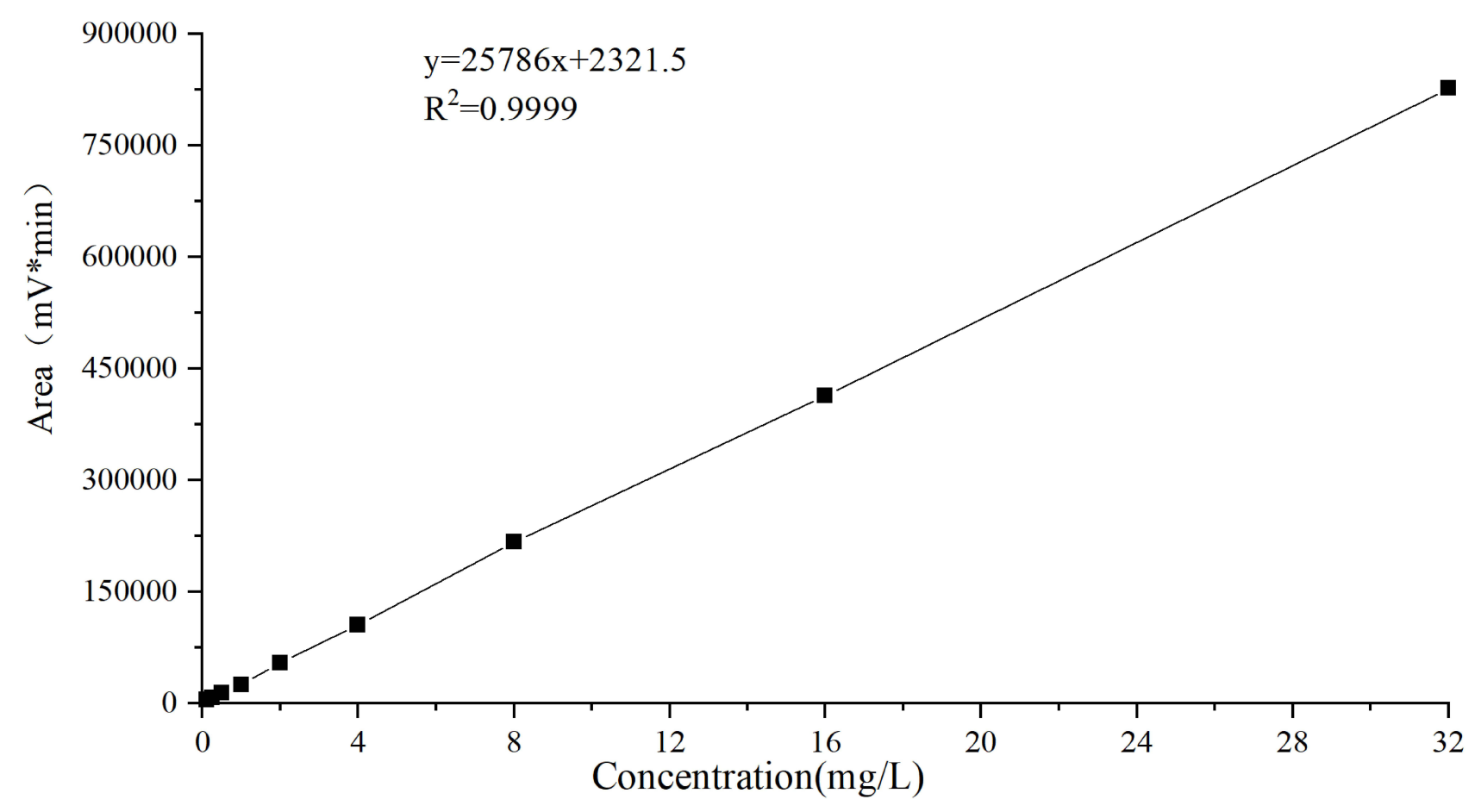

Figure 2 Standard curve. 
Table I Intra-Day Precision and Accuracy for Linezolid ( $\mathrm{n}=5$ at Each QC Level)

\begin{tabular}{|l|c|c|c|}
\hline \multirow{2}{*}{} & \multicolumn{3}{|c|}{ Quality Control Concentration (mg/L) } \\
\cline { 2 - 4 } & LQC (0.25) & MQC (16) & HQC (32) \\
\hline Mean & 0.227 & 16.26 & 33.61 \\
SD & 0.0075 & 1.22 & 0.67 \\
CV (\%) & 3.229 & 7.485 & 1.949 \\
Accuracy (\%) & 90.912 & 101.603 & 105.033 \\
\hline
\end{tabular}

the weighted calibration curves generated during the validation was 0.9999 .

\section{Precision and Accuracy}

The results for accuracy and intra- and inter-day precision for the three QC levels are provided in Tables 1 and 2; the results were found to be within the acceptable limits defined by the 2018 Bioanalytical Method Validation Guidance for Industry (FDA.2018). ${ }^{15}$ There was no bias for QC samples and the mean values were within $\pm 15 \%$ of the nominal concentrations. Imprecision was acceptable, as indicated by both intra- and inter-day coefficients of variation of $<15 \%$ at all concentrations of LNZ. Similarly, the intra- and inter-day accuracies were within $\pm 15 \%$ of the nominal concentrations.

Table 2 Inter-Day Precision and Accuracy for Linezolid ( $\mathrm{n}=15$ at Each QC Level)

\begin{tabular}{|l|c|c|c|}
\hline \multirow{2}{*}{} & \multicolumn{3}{|c|}{ Quality Control Concentration (mg/L) } \\
\cline { 2 - 4 } & LQC (0.25) & MQC (16) & HQC (32) \\
\hline Mean & 0.24 & 16.39 & 33.78 \\
SD & 0.018 & 0.72 & 1.76 \\
CV (\%) & 7.598 & 4.364 & 5.211 \\
Accuracy (\%) & 96.064 & 102.468 & 105.559 \\
\hline
\end{tabular}

\section{Stability Study}

The stability of LNZ QC samples stored at $4^{\circ} \mathrm{C}$ for up to $24 \mathrm{~h}$ in the autosampler, on the benchtop at room temperature for up to $24 \mathrm{~h}$, and under three freeze-thaw cycles in broth was evaluated. As shown in Table 3, LNZ was stable percentage accuracies for all the stability tests for LNZ were found to be $\pm 15 \%$ of the nominal concentrations at low, medium and high QC levels.

\section{In vitro PK/PD Model}

The observed concentrations of LNZ in vitro PK/PD model closely mimicked the targeted concentrations for the simulated dosing regimen (Figure 3 ). The pharmacokinetic parameters of LNZ in vitro and in vivo are shown in Table 4. There are minor difference between the experimental parameters and simulated parameters. The bacterial kill and regrowth curve is displayed in Figure 4 among control group and $600 \mathrm{mg} \mathrm{q} 12 \mathrm{~h}$ group. In the control group, the bacterial reached $7.9 \mathrm{Log} 10 \mathrm{CFU} / \mathrm{mL}$ at 48 $\mathrm{h}$ and remained. In the $600 \mathrm{mg} \mathrm{q} 12 \mathrm{~h}$ group, the Log10CFU/mL value decreased to 2.39 in the initial $24 \mathrm{~h}$. However, bacterial regrowth was observed after $24 \mathrm{~h}$ and the colony reached $5.67 \mathrm{Log} 10 \mathrm{CFU} / \mathrm{mL}$ at $48 \mathrm{~h}$ until $72 \mathrm{~h}$.

\section{Discussion}

Antibiotic resistance has become a global public health problem, especially the infection caused by multidrugresistant bacteria, which often means serious illness and high mortality. Linezolid is recommended for the treatment of community-acquired and hospital-acquired pneumonia caused by MRSA, which is one of the pathogens causing multiple-drug resistance. ${ }^{16}$ The clinically recommended intravenous dose is $600 \mathrm{mg} \mathrm{q} 12 \mathrm{~h}$, administered at $0.5 \mathrm{~h}^{1,17}$ Our groups were also interested in the activity of

Table 3 Stability Data for Linezolid in Muller-Hinton Broth; $n=5$ at Each QC Level

\begin{tabular}{|c|c|c|c|c|}
\hline Stability Test & Quality Control Concentration (mg/L) & Mean \pm SD $(\mathrm{mg} / \mathrm{L})$ & CV (\%) & Accuracy (\%) \\
\hline \multirow[t]{3}{*}{ Auto-sampler ${ }^{\mathrm{a}}$} & 0.25 & $0.233 \pm 0.00882$ & 3.795 & 93.05 \\
\hline & 16 & $16.45 \pm 0.46$ & 2.810 & 102.822 \\
\hline & 32 & $33.66 \pm 2.35$ & 6.972 & 105.185 \\
\hline \multirow[t]{3}{*}{ Bench-top ${ }^{b}$} & 0.25 & $0.26 \pm 0.00964$ & 3.7 & 104.229 \\
\hline & 16 & $16.48 \pm 0.52$ & 3.171 & 102.981 \\
\hline & 32 & $34.07 \pm 0.24$ & 0.961 & 106.459 \\
\hline \multirow[t]{3}{*}{ Freeze-thaw ${ }^{c}$} & 0.25 & $0.22 \pm 0.0075$ & 3.397 & 88.308 \\
\hline & 16 & $16.25 \pm 1.15$ & 7.091 & 101.603 \\
\hline & 32 & $33.6 I \pm 2.26$ & 6.736 & 105.033 \\
\hline
\end{tabular}

Note: ${ }^{a} \mathrm{Up}$ to $24 \mathrm{~h}$ in autosampler at $4^{\circ} \mathrm{C}$; ${ }^{\mathrm{b}}$ at room temperature for up to $24 \mathrm{~h}$; ${ }^{\mathrm{c}}$ up to three freeze-thaw cycles at $-20^{\circ} \mathrm{C}$. 


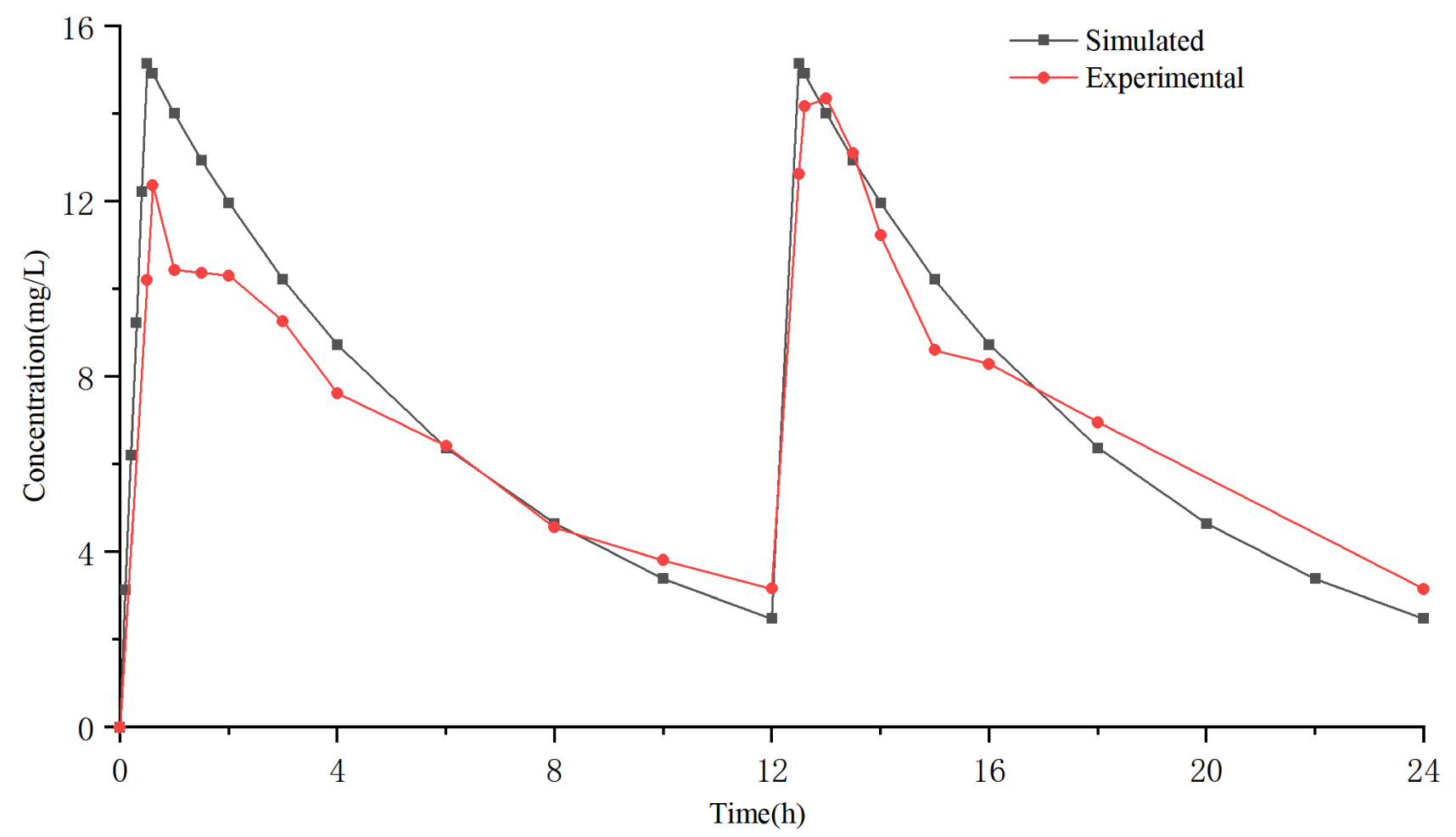

Figure 3 Concentration-time curve.

LNZ against MRSA isolates. In this study, an in vitro PK/ PD model was used to simulate the clinical intravenous dose of linezolid to observe its antibacterial activity against a clinically isolated MRSA strain.

A simple, specific and automatable HPLC assay was developed to quantify linezolid in broth using deproteinization method and UV detection. The major advantage of this assay is the sample preparation deproteinization with acetonitrile is a simple procedure, with good recoveries. The impurity are almost completely separated in the first 6 minutes of the assay and do not affect the quantitative determination of linezolid. Another advantage of the present method over previously reported methods is the application of fully automatic injection techniques and the relatively short detection time, meeting the need for rapid and accurate detection. ${ }^{7-11,18,19}$

Table 4 Pharmacokinetic Parameters of LNZ

\begin{tabular}{|l|c|c|c|c|c|}
\hline & $\mathbf{t}_{\mathbf{1 / 2}}$ & $\mathbf{A U C}_{\mathbf{0 - 1 2 h}}$ & $\mathbf{C}_{\max }$ & $\mathbf{C L}$ & $\mathbf{V}_{\mathbf{d}}$ \\
$\mathbf{( h )}$ & $\mathbf{( m g * h / L )}$ & $\mathbf{( m g / L )}$ & $\mathbf{( L / h )}$ & $\mathbf{( L )}$ \\
\hline Simulated & 4.4 & 84.66 & 15.15 & 6.006 & 38.13 \\
Experimental & 4.81 & $84.97 \pm 9.09$ & 13.84 & 5.92 & 41.07 \\
& \pm 0.90 & & \pm 1.74 & \pm 0.56 & \pm 8.95 \\
\hline
\end{tabular}

Abbreviations: $t_{1 / 2}$, half-life; AUC, area under the curve; $C_{\max }$, maximal concentration; $\mathrm{CL}$, clearance; $\mathrm{V}_{\mathrm{d}}$, volume of distribution.
As seen in Figure 3, the closeness of experimental data from the in vitro PK/PD infection model and the simulated pharmacokinetic curve up to $24 \mathrm{~h}$ suggests the reliability of the model in simulating drug concentrations over time and the concentration remained above $2 \mathrm{mg} / \mathrm{L}$ during the 3 days treatment. As shown in Table 4, there are minor differences between the experimental parameters and simulated parameters analyzed by Phoenix Winnonlin 8.3, demonstrating the successful establishment of the in vitro $\mathrm{PK} / \mathrm{PD}$ model.

The growth control group reached $7.9 \log _{10} \mathrm{CFU} / \mathrm{mL}$ at $48 \mathrm{~h}$ indicating that the in vitro PK/PD model represents cultivated bacteria well (Figure 4). In the $600 \mathrm{mg}$ q12h group, the $\log _{10} \mathrm{CFU} / \mathrm{mL}$ value decreased to 2.39 in the initial $24 \mathrm{~h}$, showed great bactericidal effect on the clinical MRSA isolate. However, bacterial regrowth was observed after $24 \mathrm{~h}$ and the colony reached $5.67 \log _{10}$ $\mathrm{CFU} / \mathrm{mL}$ at $48 \mathrm{~h}$, while $\mathrm{LNZ}$ remained above the minimum inhibitory concentration (MIC) of $2 \mathrm{mg} / \mathrm{L}$. We can also seen that the colony count remained at $5.67 \log _{10} \mathrm{CFU} /$ $\mathrm{mL}$ until $72 \mathrm{~h}$. These findings indicated the emergence of drug resistance in vitro PK/PD model. The results of oneway ANOVA (Table 5) showe that there was a statistically significant difference $(\mathrm{P}<0.05)$ in colony growth between the experimental group and the control group during the 


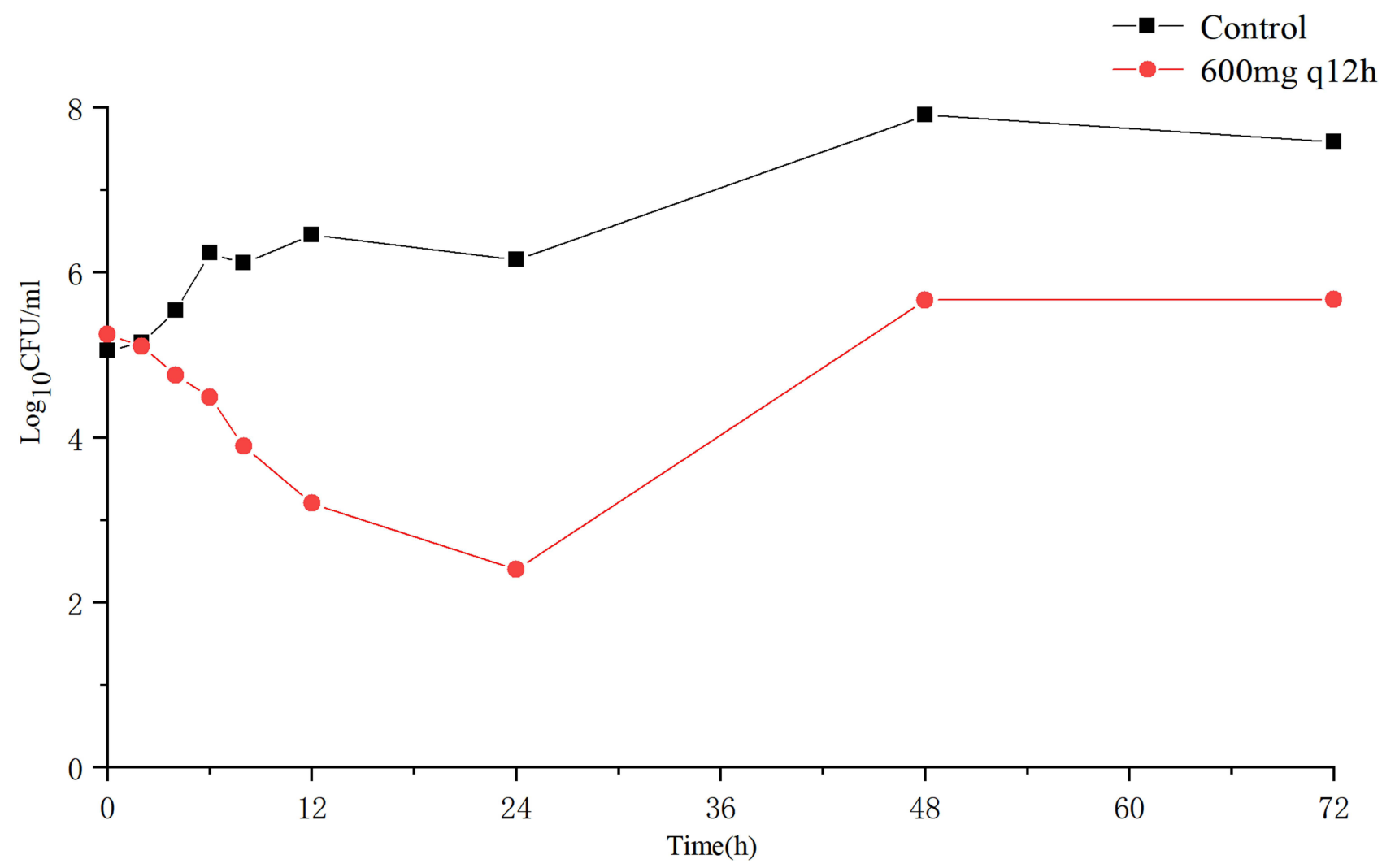

Figure 4 Bacterial kill and regrowth curve.

whole experiment period $(\mathrm{P}=0.003)$, indicating that linezolid showed bacteriostatic activity against this clinical isolate in the whole 3 days of treatment. Linezolid demonstrated bacteriostatic ${ }^{20-24}$ and bactericidal ${ }^{20,25-27}$ activities against target pathogens has been reported elsewhere. Why we can observed the regrowth of colony in the dosing group? Maybe drug resistance mutation occurred, the resistance mutation frequency of Staphylococcus to LNZ under natural conditions was $10^{-9}-10^{-11} \cdot{ }^{30}$ Boak et al ${ }^{28}$ investigated the PK/PD factors influencing emergence of resistance to linezolid in an in vitro model that similar with us, four strains including MRSA isolate has been studied. The simulation with $600 \mathrm{mg}$ q12h provided a $>3-\log _{10}$ reduction in the

Table 5 The Results of One-Way ANOVA of Logarithmic Changes About 600mg LNZ qI2h Group vs Control Group in 3 Days Simulation

\begin{tabular}{|c|c|c|c|c|c|}
\hline \multicolumn{6}{|l|}{ Test of Homogeneity of Variances } \\
\hline & & \multicolumn{2}{|c|}{ Levene Statistic } & $d f \mathbf{I}$ & $d f 2$ \\
\hline \multicolumn{2}{|l|}{ Based on mean } & \multicolumn{2}{|c|}{0.336} & 1 & 16 \\
\hline \multicolumn{2}{|l|}{ Based on median } & \multicolumn{2}{|c|}{0.222} & 1 & 16 \\
\hline \multicolumn{2}{|l|}{ Based on median and with adjusted $d f$} & \multicolumn{2}{|c|}{0.222} & I & $|5.80|$ \\
\hline \multicolumn{2}{|l|}{ Based on trimmed mean } & \multicolumn{2}{|c|}{0.323} & 1 & 16 \\
\hline \multicolumn{6}{|l|}{ ANOVA } \\
\hline & Sum of Squares & $d f$ & & $\boldsymbol{F}$ & Sig \\
\hline Between groups & 13.810 & 1 & & 12.294 & 0.003 \\
\hline Within groups & 17.973 & 16 & & & \\
\hline Total & 31.782 & 17 & & & \\
\hline
\end{tabular}


number of $\mathrm{CFU} / \mathrm{mL}$ for all four strains in 3 days assay which was differ from our study. Firsov et $\mathrm{al}^{29,30}$ applied inoculum with an $S$. aureus parent strain was supplemented with derived linezolid-resistant cells that were selected through extensive passaging on linezolid-containing media to simulate the mutation frequency and they observed the enrichment of resistant mutants with AUC/ $\mathrm{MIC}=30, \mathrm{AUC} / \mathrm{MIC}=60$ and $\mathrm{AUC} / \mathrm{MIC}=120$ groups that contained the clinical dose regimen. To our knowledge, this is the first investigation that found the loss of susceptibility of MRSA isolate to linezolid without use of mixed inoculum. The risk factors for the development of resistance, including the use of inadequate linezolid doses, long durations of therapy and the nature of the infection, have been reported. ${ }^{31-33}$ We can infer that the resistance of the MRSA to linezolid will continue to develop in the central compartment with $600 \mathrm{mg}$ q12h administration simulation.

The emergence of resistance can be explained by the hypothesis of MSW, that is the concentration range from the MIC to the mutant prevention concentration (MPC), within which it is proposed that resistant mutants are enriched or selected. ${ }^{34}$ During the treatment, the concentration of linezolid may fall within the MSW for a long time in vitro $\mathrm{PK} / \mathrm{PD}$ model. The mechanism of resistance to linezolid may be linked to the domain $\mathrm{V}$ region of the $23 \mathrm{~S}$ rRNA gene; G2576T mutation is known to be the most prevalent. $^{35}$ Closing the mutant selection window (MSW) is an effective solution to delay emergence of bacterial resistance, and there was no enrichment of resistant mutant occurred when the AUC/MIC reached $240 .{ }^{30}$ However, this value was twofold higher than that in clinical trial. Combination is another solution, Jiang et $\mathrm{al}^{36}$ observed that linezolid combined with fosfomycin closing each other's mutant selection window through MuellerHinton Agar dilution method.

The limitaion of our study was only a single linezolid regimen was simulated and the pharmacodynamic index that best predicts the development of linezolid resistance was not elucidated. Further studies evaluating a range of linezolid exposures are necessary to describe better with the pharmacodynamics of linezolid resistance. These results imply that for the treatment of MRSA infection, the usual doses and administration of linezolid need to be optimized to suppress the emergence of resistance, and this in vitro $\mathrm{PK} / \mathrm{PD}$ model can guide antibiotic studies for dose optimization.

\section{Conclusion}

We established an in vitro PK/PD model and an HPLC-UV method to measure the concentration of LNZ. The method's LLOQ of $0.125 \mathrm{mg} / \mathrm{L}$ for LNZ easily meets the requirements for drug detection well below the intended MIC of $2 \mathrm{mg} / \mathrm{L}$. The present method is simple, rapid, and sensitive, with good recoveries, and is selective and quantitative for the in vitro evaluation of linezolid efficacy. In vitro experimental data were similar to the simulated plasma data, further confirming the appropriateness of the experimental design to quantitate antibiotics and to study the emergence of antimicrobial resistance in real time. An emergence of resistance was occurred in LNZ 3 days administration simulation. These results also indicate that the usual clinical dose of linezolid should be optimized to suppress the emergence of resistance.

\section{Acknowledgments}

This study was supported by the National Natural Science Foundation of China (81173133), the Fund of Excellent Talents in Colleges and Universities of Anhui Province, China (gxbjZD06), and the Fund of Academic Leaders of Anhui Province, China (2015D068).

\section{Disclosure}

The authors report no conflicts of interest in this work.

\section{References}

1. Perry CM, Jarvis B. Linezolid: a review of its use in the management of serious gram-positive infections. Drugs. 2001;61(4):525-551. published correction appears in Drugs 2003;63(19);61(4):2126. doi:10.2165/00003495-200161040-00008

2. Doern CD, Park JY, Gallegos M, et al. Investigation of linezolid resistance in staphylococci and enterococci. J Clin Microbiol. 2016;54(5):1289-1294. doi:10.1128/JCM.01929-15

3. Chen H, Li L, Liu Y, et al. in vitro activity and post-antibiotic effects of linezolid in combination with fosfomycin against clinical isolates of Staphylococcus aureus. Infect Drug Resist. 2018;11:2107-2115. doi:10.2147/IDR.S175978

4. Zhou YF, Xiong YQ, Tao MT, et al. Increased activity of linezolid in combination with rifampicin in a murine pneumonia model due to in vitro. J Antimicrob Chemother. 2018;73(7):1899-1907. doi:10.1093/ jac/dky129

5. Louie A, Maynard M, Duncanson B, et al. Determination of the dynamically linked indices of fosfomycin for Pseudomonas aeruginosa in the hollow fiber infection model. Antimicrob Agents Chemother. 2018;62(6):e02627-17. doi:10.1128/AAC.02627-17

6. Dryden MS. Linezolid pharmacokinetics and pharmacodynamics in clinical treatment. J Antimicrob Chemother. 2011;66(4):iv7-iv15. doi:10.1093/jac/dkr072

7. Boak LM, Li J, Nation RL, Rayner CR. High-performance liquid chromatographic method for simple and rapid determination of linezolid in human plasma. Biomed Chromatogr. 2006;20(8):782-786. doi:10.1002/bmc.597 
8. Li J, Rayner CR, Dixson S, et al. Simple method for the assay of linezolid in brain heart infusion broth by high-performance liquid chromatography. Biomed Chromatogr. 2004;18(1):1-5. doi:10.1002/ bmc. 283

9. Toutain J, Boselli E, Djabarouti S, et al. Determination of linezolid in plasma and bronchoalveolar lavage by high-performance liquid chromatography with ultraviolet detection using a fully automated extraction method. J Chromatogr B Analyt Technol Biomed Life Sci. 2004;813(1-2):145-150. doi:10.1016/j.jchromb.2004.09.030

10. Davis LT, Kumar N, Nijm LM, et al. An adaptable HPLC method for the analysis of frequently used antibiotics in ocular samples. J Chromatogr B Analyt Technol Biomed Life Sci. 2010;878 (26):2421-2426. doi:10.1016/j.jchromb.2010.08.001

11. Ba BB, Nso BB, Quentin C, et al. Determination of linezolid in growth media by high-performance liquid chromatography with on-line extraction. J Chromatogr B Analyt Technol Biomed Life Sci. 2007;854(1-2):104-108. doi:10.1016/j.jchromb.2007.04.011

12. CLSI. Methods for Dilution Antimicrobial Susceptibility Tests for Bacteria That Grow Aerobically. 11th ed. CLSI standard M07. Wayne, PA: Clinical and Laboratory Standards Institute; 2018.

13. Stalker DJ, Jungbluth GL, Hopkins NK, et al. Pharmacokinetics and tolerance of single- and multiple-dose oral or intravenous linezolid, an oxazolidinone antibiotic, in healthy volunteers. $J$ Antimicrob Chemother. 2003;51(5):1239-1246. doi:10.1093/jac/dkg180

14. Stalker DJ, Jungbluth GL. Clinical pharmacokinetics of linezolid, a novel oxazolidinone antibacterial. Clin Pharmacokinet. 2003;42 (13):1129-1140. doi:10.2165/00003088-200342130-00004

15. Bioanalytical method validation guidance for industry. Available from: http:/www.fda.gov/Drugs/GuidanceComplianceRegulatoryInformation/ Guidances/default.htm. Accessed November 22, 2021.

16. Lodise TP Jr, McKinnon PS. Burden of methicillin-resistant Staphylococcus aureus: focus on clinical and economic outcomes. Pharmacotherapy. 2007;27(7):1001-1012. doi:10.1592/phco.27.7.1001

17. Chavanet P. The ZEPHyR study: a randomized comparison of linezolid and vancomycin for MRSA pneumonia. Med Mal Infect. 2013;43(11-12):451-455. doi:10.1016/j.medmal.2013.09.011

18. Fernandes GFDS, Salgado HRN, Santos JLD. A critical review of HPLC-based analytical methods for quantification of Linezolid. Crit Rev Anal Chem. 2020;50(3):196-211. doi:10.1080/10408347.2019.1605876

19. Kumar L, Yadav YS, Rathnanand M. Simultaneous determination of linezolid and levamisole hydrochloride in a fixed dose combination. Indian J Pharm Educ Res. 2017;51(4):613-619. doi:10.5530/ijper.51.4.91

20. Allen GP, Cha R, Rybak MJ. In vitro activities of quinupristin-dalfopristin and cefepime, alone and in combination with various antimicrobials, against multidrug-resistant staphylococci and enterococci in an in vitro pharmacodynamic model. Antimicrob Agents Chemother. 2002;46(8):2606-2612. doi:10.1128/AAC.46.8. 2606-2612.2002

21. Cha R, Akins RL, Rybak MJ. Linezolid, levofloxacin, and vancomycin against vancomycin-tolerant and fluoroquinolone-resistant Streptococcus pneumoniae in an in vitro pharmacodynamic model. Pharmacotherapy. 2003;23(12):1531-1537. doi:10.1592/phco.23.15.1531.31964

22. Gunderson BW, Ibrahim KH, Peloquin CA, et al. Comparison of linezolid activities under aerobic and anaerobic conditions against methicillin-resistant Staphylococcus aureus and vancomycin-resistant Enterococcus faecium. Antimicrob Agents Chemother. 2003;47 (1):398-399. doi:10.1128/AAC.47.1.398-399.2003

23. Jacqueline $C$, Batard E, Perez L, et al. In vivo efficacy of continuous infusion versus intermittent dosing of linezolid compared to vancomycin in a methicillin-resistant Staphylococcus aureus rabbit endocarditis model. Antimicrob Agents Chemother. 2002;46 (12):3706-3711. doi:10.1128/AAC.46.12.3706-3711.2002
24. LaPlante KL, Rybak MJ. Impact of high-inoculum Staphylococcus aureus on the activities of nafcillin, vancomycin, linezolid, and daptomycin, alone and in combination with gentamicin, in an in vitro pharmacodynamic model. Antimicrob Agents Chemother. 2004;48 (12):4665-4672. doi:10.1128/AAC.48.12.4665-4672.2004

25. Cha R, Brown WJ, Rybak MJ. Bactericidal activities of daptomycin, quinupristin-dalfopristin, and linezolid against vancomycin-resistant Staphylococcus aureus in an in vitro pharmacodynamic model with simulated endocardial vegetations. Antimicrob Agents Chemother. 2003;47(12):3960-3963. doi:10.1128/AAC.47.12.3960-3963.2003

26. Cha R, Rybak MJ. Linezolid and vancomycin, alone and in combination with rifampin, compared with moxifloxacin against a multidrug-resistant and a vancomycin-tolerant Streptococcus pneumoniae strain in an in vitro pharmacodynamic model. Antimicrob Agents Chemother. 2003;47 (6):1984-1987. doi:10.1128/AAC.47.6.1984-1987.2003

27. Oramas-Shirey MP, Buchanan LV, Dileto-Fang CL, et al. Efficacy of linezolid in a staphylococcal endocarditis rabbit model. J Antimicrob Chemother. 2001;47(3):349-352. doi:10.1093/jac/47.3.349

28. Boak LM, Li J, Rayner CR, et al. Pharmacokinetic/pharmacodynamic factors influencing emergence of resistance to linezolid in an in vitro model. Antimicrob Agents Chemother. 2007;51(4):1287-1292. doi:10.1128/AAC.01194-06

29. Firsov AA, Alieva KN, Strukova EN, et al. Testing the mutant selection window hypothesis with Staphylococcus aureus exposed to linezolid in an in vitro dynamic model. J Antimicrob Chemother. 2017;72(11):3100-3107. doi:10.1093/jac/dkx249

30. Firsov AA, Golikova MV, Strukova EN, et al. In vitro resistance studies with bacteria that exhibit low mutation frequencies: prediction of "antimutant" linezolid concentrations using a mixed inoculum containing both susceptible and resistant Staphylococcus aureus. Antimicrob Agents Chemother. 2015;59(2):1014-1019. doi:10.1128/ AAC.04214-14

31. Birmingham MC, Rayner CR, Meagher AK, et al. Linezolid for the treatment of multidrug-resistant, gram-positive infections: experience from a compassionate-use program. Clin Infect Dis. 2003;36 (2):159-168. doi:10.1086/345744

32. Pai MP, Rodvold KA, Schreckenberger PC, et al. Risk factors associated with the development of infection with linezolid- and vancomycin-resistant Enterococcus faecium. Clin Infect Dis. 2002;35(10):1269-1272. doi:10.1086/344177

33. Roberts SM, Freeman AF, Harrington SM, et al. Linezolid-resistant Staphylococcus aureus in two pediatric patients receiving low-dose linezolid therapy. Pediatr Infect Dis J. 2006;25(6):562-564. doi:10.1097/01.inf.0000219401.70804.1a

34. Firsov AA, Smirnova MV, Lubenko IY, et al. Testing the mutant selection window hypothesis with Staphylococcus aureus exposed to daptomycin and vancomycin in an in vitro dynamic model. J Antimicrob Chemother. 2006;58(6):1185-1192. doi:10.1093/jac/ dk1387

35. Wu D, Yan B, Yang X, et al. Whole-genome sequencing for detecting linezolid resistance in a patient with persistent methicillin-resistant Staphylococcus aureus infection during linezolid exposure. Int J Antimicrob Agents. 2020;55(1):105819. doi:10.1016/j.jjantim icag.2019.09.023

36. Jiang L, Xie N, Chen M, et al. Synergistic combination of linezolid and fosfomycin closing each other's mutant selection window to prevent enterococcal resistance. Front Microbiol. 2021;11:605962. doi:10.3389/fmicb.2020.605962 


\section{Publish your work in this journal}

Infection and Drug Resistance is an international, peer-reviewed openaccess journal that focuses on the optimal treatment of infection (bacterial, fungal and viral) and the development and institution of preventive strategies to minimize the development and spread of resistance. The journal is specifically concerned with the epidemiology of antibiotic resistance and the mechanisms of resistance development and diffusion in both hospitals and the community. The manuscript management system is completely online and includes a very quick and fair peerreview system, which is all easy to use. Visit http://www.dovepress.com/ testimonials.php to read real quotes from published authors. 